\title{
The Prospect of Ethnic Nationalism in Iranian Azerbaijan
}

\author{
Prof. Dr. Ghadir Golkarian
}

Near East University

\begin{abstract}
Nationalism in Iran has got a history full of remarkable ups and downs. The emergence of nationalism in Iran mainly belongs to the contemporary time and specially goes back to the period of time after constitutional revolution. By focusing on archaism without considering Iran Islamic era and emphasis on the separation of religion and politics, nationalism in Iran had been the consequence of romantic imaginations about Iran's past and Iranian identity which has always been coincide with extremes and lack of consideration of historical facts, traditions and Iranian rich and valuable culture.

As Iranian nationalism was promoted as a dominant discourse in the era of Reza Shah and Mohammad Reza Shah Pahlavi, ethnic nationalism became more prominent in the same way. The dynasty let the ethnic reactions increase due to empathy (impose of idea) of idea of "one flag, one language, one nation" and it is noteworthy that as the result of this policy, ethnic nationalism and the quest for identity among Azeri Turks and Kurds of Iran raised. In this article we are trying to illustrate some main dimensions of ethnic nationalism in Iranian Azerbaijan and also study its origin regarding the present outlook.
\end{abstract}

Keywords: Nationalism, ethnic nationalism, state- nation, Iranian Azerbaijan

\section{INTRODUCTION}

The phenomenon of nation-state formation and the rise of nationalism in Iran is one of the considerable cases in this country, number of Iranian sociological issues scholars and researchers have stated different point of views and opinions and also have provided various analysis about the issue.

In the field of international relations and in Iran as well, nationalism has always been a very challenging phenomenon in terms of social, cultural, political as well as economical aspects and in contemporary Iran and specially after Islamic revolution it is formed in a very extreme () way against Islamic ideologies and ideas. However, the question that raises here is that how nationalism in Iran asses ethnic nationalism considering the long history the issue of nationalism itself has got inside the country. Due to the fact that Iran is a country with many nations including Turks, Kurds, Arabs, Persians, Balouchis, Gilanis, Tat, and khorasani, how Iran digest and accepts the issue of ethnic nationalism though? Does Iranian nationalism give any value to or care about races and their quest for identity?

In the present study we are trying to discuss the issue of ethnic nationalism in Iran, considering the demography of the country and high population of Azeri Turks, we will study Turkish nationalism in Iran. Azerbaijani Turks in Iran make up almost half of the population of the country which is over 30 million people of total population.

\section{The Development Process of Nations And Nationalism}

The definition of nation: there are various definitions for the term "nation", some of them are as follows:

A. Nation is a number of people shown on a geographical map or inside certain borders. [1]

B. Nation is an independent political group with a shared worldview and cultural heritage.[2]

C. Nation is a group of people who perceive themselves as a part of a vast community without knowing or meeting the other members of the group.

These sort of perceptions do not exist by themselves or on a nationwide scale and need to be promoted. Common decent or kinship is one of the important elements in creation of a nation. 
Considering this fact, nation is a group of people who believe in their shared ancestry as Benedict Anderson (1983) states that nation is an imagined political community because the members "will never know most of their fellow- members or meet them, yet in the mind of each lives the image of their communion".[3]

It seems that mentioned definitions do not accurately describe the term "nation". So each state and its operational context meaning each country is adorned with a culture which is enriched through centuries and is inherited to them. There is no nation or state that has been aside from the impact of the national popular culture (like common aspects of ethnic group in a country). These social aspects of popular culture manifests in the form of general social facts or national reality. These national realities constantly change and evolve along with social changes. [4]

In the current definition, the concept of popular aspects of culture or common cultural heritage or belief in an imagination about the common decent is counted as one of the characteristics of a nation.

Iran's geographical scope includes different ethnics and races such as Persian, Arabs, Balouchis, Turks, Turkmens, Kurds, Lors, etc. despite ethnic differences, they all recognize themselves as Iranians with strong Iranian Identity.

The Iranian identity of Iran nation is related to its ethnics and races. Although each of them is placed as a member of a united body, but they all have an Iranian identity which is shared throughout the history.[5]

Comte de Gobineau states that "Iranians are people who are very different from us, they have interbred with different races but they have kept their identity. These people have interconnected their ideas and interests and are intertwined like a network so that each of them can be pulled like a string without having to be tied. Common sense is an important part of Iranians moral heritage."[6]

Many researchers believe that the phenomenon of nation building in Iran is quite old and they have tried to connect nationalism to the ancient times of Iran. As an example, self awareness as a nation among Iranians has got such an old roots that goes back to the time of Avesta (an ancient religious book of Iranians). In the Avesta Iranian people and their language is mentioned, it is written that they used to live in a land called "Iranvich" with a king, certain prophets and they lived with national and religious aspirations.

In Zoroastrian religious texts and even in Shahnameh which is composed by the great Ferdowsi we deal with terms such as Iran and Iranshahr. In the meantime, in shahnameh, there are some stories about the great war between Iran and Turan. So it seems that nationalism in Iran has got historical roots, contrary to some researchers who believed that nationalism is a phenomenon of reformism or is raised from Westphalia story in 1348. Iranian nationalism is not even compatible with believes of French researchers about the French revolution in1789.

Iranian nationalism has shared common climate and land and boarders, common history and civilization, common race and blood relationship and it also shares joint geo-political and economic institutions.

Despite customs and other components of their nation, Iranian Azerbaijan Turks recognize themselves inside the boarders of Iran and they share common interests. As the result, we should deal with the ethnic nationalism in Iranian Azerbaijan from this perspective.

\section{IRANIAN AZERBAIJAN}

Azerbaijan is located in the northwest part of Iran and has always been the head of triangle to defend Iran against invaders and enemies such as Russians and Ottomans. According to Stalin, Iranian Azerbaijan was a ripe ready to eat fruit in 19461325. Soviet troops had occupied the region and Soviet puppet government was ruling in the Azerbaijan. America and Britain were trying to take their troops and forces out of war situation and they were also trying not to participate in new clashes. Iran and the central government was too weak to protest and was just showing some light objections against Soviet government. In this situation, integration of Iranian Azerbaijan to Soviet was easier than annexation of Eastern Europe into the Soviet empire. On the other hand, since Azerbaijan was sharing boarders with Turkey as well, the supporters of unity of Turkish speaking lands in Turkey were asking the annexation of Azerbaijan to their own country. [7] 
Studying the mentality and attitudes of people in Azerbaijan and their perspective of nationalistic ideas and religious beliefs according to the country they felt belonging to, we can realize that basically, Soviet or pan Turks expectations about the separation of Azerbaijan from Iran has been a lot since there has been no desire for them to separate from Iran. Without any doubt, the opinion of people and nationalists of Iran had been clear and free of any ambiguity: "Azerbaijan is an integral part of Iran".

The future prospect of ethnic nationalism in Iranian Azerbaijan requires a deep look. Beside the introductory and general remarks, there is a need to consider theoretical approaches and factors affecting the formation or intensification of ethnic nationalism in multiethnic societies as well.

We are going to discuss ethnicity in Iran and especially Azerbaijan ethnic minorities and issues will be studied. The outlook of ethnic nationalism in Azerbaijan will be discussed in three dimensions:1) ideology or ethnic movement objectives in Azerbaijan, 2) the social status of ethnic movement active forces 3) ethology of elites and social messes, and finally we will conclude.

We should mention some points here, the possibility of presenting a vision about near future and the process of ethnic nationalism in any multiethnic society including Iran requires a series of reflections and studies related to various research fields. Because nationalism, ethnicity and nepotism are interdisciplinary fields and various fields such as sociology, politics, international relations, comparative politics, social psychology, basic rights, political economy, international law and even disciplines such as anthropology should be included.

The other point is that, becoming inspired by various approaches of some theories the affecting factors which are crucial information or intensification of ethnic nationalism in multiethnic societies are categorized in seven categories. The purpose of this kind of categorization in to specify the exact position of the issue among affecting factors in formation of ethnic nationalism and also the issue can be presented in one of the mentioned frameworks.

\section{EThNic Nationalism in Azerbaijan}

It is necessary to define the nature of ethnic nationalism in Iran and Azerbaijan which is a definition of ethnic issues in Iran: "ethnic nationalism is a socio-political movement or force which drives from ethnic characteristics and seeks to achieve some socio-political and ethnic demands". Considering ethnic ideologies, methods and mechanisms to achieve the demands and its scope and depth, it can have various types. So, nationalism has different types that can take various form in 3 dimensions as: ideology, methods and mechanisms on follow up on demands, and social status of ethnic activists.

\section{A. Factors Affecting the Formation of Ethnic Nationalism}

Factors affecting formation or intensification of ethnic nationalism in multiethnic societies are numerous due to the specific demands of the community. The outlook of intensification or weaken the ethnic nationalism in each country is directly associated with these conditions. In fact, these factors specify the future trends of ethnic nationalism.

The first factor is that, in terms of ethnic relations, how is the distribution of power recourses in the community? From the perspective of economic, is the system of distribution of power resources working based of equality or whether it is similar to the other models and is based on core- periphery?

From political point of view, are the relations between nations-(minority and majority of ethnic groups) based on cooperation or Authoritarianism? In other words, is is democratic or undemocratic?

From cultural perspective, is the distribution of power recourses exclusivist? Is that ethnic oriented or nation oriented? So, the first factor is about the distribution of power recourses and it is necessary to have adequate knowledge about the nature and types of ties and relationships in the levels of power to be able to provide a real outlook of the ethnic nationalism in a country.

The second factor that can affect the ethnic nationalism in every country is related to the situation of ethnic nationalism movement considering 3 dimensions of ideologies, methods and mechanisms on follow up on demands and social status that should be defined as "current situation and the trends governing it".

Another influential element or the third factor is the historical experience of interactions and relationships among people. Have the relations between the nations been based on dominant and 
submissive behavior? Has the social life in the given country been based on federal, autonomous or feudal rules? Experiencing each one of these types of social lives can have great impact on the current state and future of ethnic nationalism in each country.

The fourth factor is related to the future reactions of center of powers (other powerful countries) regarding the ethnic issues in a particular country. Whether organizations and regional and transregional powers will follow the ethnic issues of a country for their own specific motivations or will stay indifferent? This issue has been very important for many multiethnic communities in the last two decades and will be important in future as well. In other words, the status of friends and enemies of the central government or the dominant ethnic is one of the influential factors in ethnic nationalism in a country. This factor is also very variable and fluid. Because it is possible that today's enemies of a central government become the close friend in the future and help the central government in dealing with the foreign agents.

The fifth factor is the geomantic and geographical condition of an ethic group in the community. In this perspective several indicators and components can be raised. What is the ratio of minority comparing to the majority in a particular society? How's the status of the ethnic lands? To what extend the nations on the neighboring countries are sharing the same identity and have similarities with them? How are social gaps, are they complex, simple or multidimensional? Although, cultural, economical and communication capabilities of a ethnic groups in a particular land with their neighboring country can have a very significant affect on the ethnic nationalism.

The sixth factor asks about the process of nation -state building in a country. In other words, it seeks whether the country has passed through multiple crises successfully? Or it is still dealing with building a nation or state? In order to provide a perspective for the future, it is necessary that each and every crisis be studied carefully.

The seventh influential factor on ethnic movements deals with the attitudes and tendency of the ethnic groups towards national identity, national interest, national security and national government. And whether the attitudes of the ethnic groups to the mentioned components and concepts is consistence with dominant approaches of central government? Is there any other definition for these components in a particular ethnic group? Obviously, getting to know such approaches requires a series of large scale survey projects, and if national authorities are seeking to solve ethnic issues, it is essential that such research project place on the agenda.

\section{B. The Status of Ethnic Nationalism in Azerbaijan}

After this introduction and reviewing theoretical complexity of ethnic issues and affecting factors on the aggravation or mitigation of ethnicity, here we will discuss ethnic movement in Azerbaijan. However, this debate is evaluated in terms of the second factor amongst seven mentioned factors. The focus is on the ethnic ideology of this movement, yet, mechanism and procedures of demands and also the social status of the movement will be investigated. The methodology is based on the ethology of social groups and messes in 1990s.

\section{Ethnic Ideology}

The nature of ethnic ideology can play a very crucial role in the prospect of ethnic nationalism in Iran, there for, in order to understand the nature of ethnic goals we should raise this question: Is ethnic ideology in Iranian Azerbaijan indicates the authenticity of Azerbaijanis and repulse other ethnic groups?[8]

A brief answer to this question is based on observations, experiences, reviewing the press, campaign activities and some writings works and books of thinkers and intellectuals of Azerbaijan. Before addressing this discussion, it is important to note that this study relies on behavior and attitudes available in the society throughout press, meetings, articles of associations, election campaign speeches, etc.

When we talk about ethnic movement ideology or ethnic nationalism, we should discuss the issue based on what is actually happening inside the society and we must ignore what is discussed outside the country or what is raised by the opposition groups against the system. Meaning, the present study is done with emphasize on press and social media and behavior of domestic elites and messes which is a issue that everyone can inspect. It is not deniable that the area of ethnic ideology in Azerbaijan is 
based on ethnic gap, this idea is shared among elites and some political activists and intellectuals, and of course, this is the matter that should be investigated. However, the mentioned distinction and ethnic gap does not indicate the authenticity of Azerbaijanis comparing to the other races or rejecting the central government, but, it is based on a set of demands and requests in order to eliminate discriminations especially in cultural and economical areas. 70 to 80 percent of these demands which are raised and asked several times in press and parliament campaign speeches have mostly rely on cultural demands. The new generation of Azeri intellectuals or educated people are mostly requesting for fulfillment of some the demands and cultural and ethnic requirements. Thus, in ethnic ideology of elites or Azeri ethnic activists, a series of concepts or terms that exist in the literature of nationalist forces, are not used. Therefore, the intellectual driving forces in ethnic Azerbaijan movement is based on distinctions and cultural features and the main focus of this movement is trying to fulfill some pending principles of the constitution and also eliminating restrictions on cultural activities.

That is why the ethnic ideology of the Azeri activists and elite does not contain a series of concepts or terms that are commonly found in the leftist or socialist literature. Therefore, the intellectual driving force of Azerbaijan's ethnic movement is based on cultural characteristics and distinctions. The movement is also characterized by the collective effort to fulfill some of the pending principles of the constitution and remove restrictions on cultural activities. Overall, the intercultural approaches of Azeri elite and personalities can be formulated as follows: a democratic approach to politics and decentralization of political power as one of the fundamental demands of the movement, an approach which extensively conforms to the 22 May Movement (Khordad 2) while differing from it on the issue devolution of power to local authorities. It must be mentioned that even in the 22 May Movement there were individuals and groups who emphasized decentralization and delegation of power to local authorities. But the Azeri Movement adopts an egalitarian approach in the social and economic sphere and a pluralist one to culture. They demanded the government pay due attention to the language and culture of Azerbaijan and make some arrangements to safeguard this culture. In general, from an intellectual point of view it should be noted that the Azeri movement has been a reliable source of support for May 22 Movement in recent years. Also, the Azeri activists have made considerable contributions to furthering the objectives of the May 22 Movement at different levels of the society including social masses, students, the middle class as well as the political and cultural elite. However, in the last year or two, the full support of the Second of Khordad Movement has faced uncertainty and its efficiency and successfulness at a national level has been questioned. In Azerbaijan, the message of the May 22 Movement has gradually been viewed with distrust and even subjected to criticism and protests by some political, media and academic activists some of whom believe that the May 22 Movement failed to board ethnic groups on 'the train of reforms'.

\section{Social Status and Practices on Ethnic Demands}

Based on a conventional division, social activists of a movement are divided into three levels: as the masses or The basement of the pyramid, cultural and political elites or top of the pyramid and middle levels of the movement which includes conscious social activists particularly students and graduates.

Social basement of Azerbaijan movement can be checked in all these three levels. It is also possible to add some of politicians and government officials to the social basement on the top level of the pyramid. The combination of the social basement of this movement has got some similarities to the great movement of May $23^{\text {rd }}\left(2^{\text {nd }}\right.$ of khordad), the only difference is that social inclusion of this movement is not that much strong.

A comparative review can illustrate the similarities of these two movements in terms of social status. In fifth period of parliamentary election on 1995, one of the candidates from Tabriz proposed some plans and goals based on ethnic and cultural demands. If we compare social acceptance of this candidate in 1995 with the elected president in 1997, we can find strong similarities in terms of messes turnout that could not be found before. However, the presidential candidate had trans- regional and trans- ethnical approaches to Reform, and the parliament candidate in Tabriz had raised ethnical and cultural approaches and demands. It should be noted that the ethnic consciousness, which is the basis of political activities and movement among messes in Azerbaijan, is not as extended as $2^{\text {nd }}$ of khordad movement. I should mention that the main social basis of this movement in among students and graduates of universities who are playing a crucial role in ethnic self-consciousness in the social strata especially the urban middle class. They are the main link between social mess and socio cultural elites and they also have a very important role in different socio-political arena. 
In the following, we discuss the activities and movements of some elites.

\section{The Ethnic Elites and Activists}

Elites and some of the authors are researchers and thinkers who are mainly work in fields of literature, history, language, and generally cultural characteristics of Azerbaijan. The activities of cultural and scientific elites in 1990s shows a cultural movement with a gradual expansion comparing to 1980s and years before that. In other words, with considering cultural activities between the years from 1920 to 1990 and comparing them with cultural and scientific activities s in 1990s, we come to remarkable results in the field of cultural heritage of Azerbaijan. In addition to writing hundreds of books which are mostly research based (and also poetry), considerable number of books have been compiled and written about different subjects such as Azeri Turkish language, the history of Azerbaijan and IranianTurks, different cultural themes, famous characters and music. Although, compiling Authoritative dictionaries in Turkish language and translating multi volume dictionaries into Azeri Turkish are some of the cultural activities of Azeri authors in the field of linguistics. Compiling multivolume encyclopedia of Character Recognition is one of the research activities of Azerbaijan authors. In one of the encyclopedias which was published in 2001, 3000 people including sociopolitical and cultural figures of Azerbaijan were introduced. holding up Specialized scientific seminars in the field of linguistics, to develop a common orthography and reading, holding Turkish language teaching and history of Iranian Turks classes in NGOs and private universities, attending students circles to give speech, and recently, trying to establish scientific and cultural institutions are some of the Azerbaijan elite's cultural activities that also presents institutionalization spontaneous movements of elites. On the case of attempting to organize research and cultural activities, we can refer to the plan of some of the cultural figures in Azerbaijan to establish a center or institute of geology of Azerbaijan in Tabriz. According to the proposal, the recognition of research on the history of Azerbaijan and development of studies in different cultural domains and the language of Azerbaijan are some of the main provisions of the plan. The fundamental purpose of establishing the Azerbaijan institute is to regulate and also focus on research activities and also recognition and criticizing historiography in Pahlavi era. The mentioned movement can be considered as an example of institutionalization motion of scientific and cultural activities of elites. Publishing around 60 journals in different provinces is one of the other activities which could be the subject of special investigation study. [9]

\section{Students and Academics}

Students and other educated strata are the main social base of ethnic Movement in Azerbaijan, as they have the opportunity to gain ethnic and social level awareness and transfer it to the society. It can be note that educated sector and students receive the main idea from scientific and cultural elites and they play a very significant role in wide spreading ethnic consciousness among social messes. The turning point of identitism activities among the students and some academics started in 1993 when the poll (survey) section of one of the institutions, most probably broadcasting, conducted a survey in 20 educational districts in Tehran raising some questions for Tehrani students asking their opinion about Azerbaijanis and Turks in general, for example, they were asked whether they feel comfortable if their neighbor is a Turk? Do you accept if your sister marries a Turk? Do you feel comfortable if your college or neighbor be a Turk?

There could be different motivations for such a survey, and it is possible that contrary to the interpretations of Azerbaijani students, the conducted survey has been just a sociological research and nothing more. Opposing the conducted survey, Azerbaijani students showed their objection in Tehran University and later in Tabriz through protest and moved to downtown, they also protested on Friday prayers as well. This was the first time that students were showing their objection against an ethnic issue. This movement raised as a political phenomenon and ethnic issue not only in Tabriz but also all over the country. As the result, the IRIB (Broadcasting) was forced to announce on the News that the broadcasting is not related to the survey and they have not conducted the poll. However, this movement was a turning point for the beginning of some identitism and ethnic awareness (consciousness).

Other important areas of student activities involved elections. Attempts to orienting public opinion in line with ethnic as well as certain regional demands have been growing. Other student activities 
included organizing conferences and student seminars in various cities, celebrating contemporary scientific or historical figures of Azerbaijan, holding certain meetings, issuing statements on different occasions, and writing letters to the heads of state to express ethnic demands or object to the activities of some government organizations. Over the past four years, students have signed and sent out a total of 17 petitions to the heads of the three government powers and other organizations. These petitions and other letters demonstrate students' sensitivity towards state-related issues, policies as well as the behaviors and personalities of government figures. This suggests that students have on various occasions expressed specific reactions to certain behaviors and policies.

In terms of cooperation, activities and interactions between students and the political elite, particularly the local government officials, it is important to note that during the mid-1990s there was a gaping intellectual gap between the students and the governing elite including members of the parliament and certain government officials such as the provincial governors, governors, and others. In other words, MPs in the first half of 1990 adhered to a very conservative policy towards ethnic and cultural demands, regarding such movements with suspicion and a reluctance to endorse them. As a result, they strongly shunned from any form of cooperation with these movements. For example, we should study the outcome and the way students and the representatives of Iranian Islamic Parliament interacted during the 2003 joint conference. At this meeting nearly 10 representatives from various cities of Azerbaijan were invited to Sheikh Morteza Ansari Hall at the Law School of Tehran University to review and discuss certain problems and issues. However, the extent of the intellectual divide between the students and the MPs and their disagreements on issues including even how the event was organized and the language used in some of the papers were so severe that the meeting finally ended in tension and escalation of disagreements.

This trend, however, has significantly alleviated in recent years. For example, in the electoral programs of Tabriz's first MP for the sixth round of parliamentary elections, the implementation of Article 15 of the Constitution through the provision of literary conferences, compilation of the Azerbaijani literature, the creation of the Academy of Literature and Art of Azerbaijan, preparation and the presentation of legislative initiatives for teaching Azerbaijani language and literature in higher and public education were introduced. This trend was unprecedented before and during the 1990s. therefore, prior to this there was great apprehension amongst representatives and political officials who were cautioned to absolutely refrain from engaging in such issues as they were considered dangerous and macabre. Also, the third person who was elected representative of Tabriz in the sixth round of parliamentary elections had introduced a new outlook to pursuing ethnic demands in his preelection speeches and campaign leaflets, calling for an end to viewing the language, literature and culture of ethnic minorities and the people of Azerbaijan as a threat to security. In addition, for the analysis of the views and attitudes of other MPs reference can be made to interviews conducted with 20 members of the parliament 16 of whom expressed favorable views toward student activities in the realm of ethnic demands. Therefore, it is fair to say that the alleviation of MPs attitudes to ethnic demands in the past few years has been remarkable and indicative of the prevalence of this movement among government elites. To cite an example, in a recent student gathering organized by Azerbaijan University Community four Azerbaijan MPs expressed their explicit support towards students' cultural activities and legal demands. The mitigation of Azerbaijan MP's mentality towards ethnic issues is growing at such a pace that two periodicals (one weekly and one monthly) specializing in Azerbaijan issues were published under the editorialship of two Tabriz MPs. [10]

To obtain relative familiarity in this area some of the goals set forth in one of the weeklies published by a Tabriz MP are pointed out here. Some of the areas this weekly has designated for itself include: preparation of national and regional news with a focus on Turkish-speaking areas; international news related to Iran and the mentioned areas; writings and articles on the development of cities in West and East Azerbaijan, Zanjan, and Ardebil; education, employment, migration and urbanization problems, etc.; comparison of industrial, economic, mining, and export indices of the provinces covered by the publication; preparing analysis and reports on domestic issues and neighboring countries and other countries in the world; commemorating historical and literary figures, literary works, historical backgrounds, writers, artists, and poets; upholding the cultural heritage and antiquities of Eastern and Western Azerbaijan, Ardabil and Zanjan; Turkish tales, stories and folklore, cinema, theater, music, dance, painting, sculpture, literature, poetry and ethnological issues, lexicography, climatology; customs and beliefs of the people, coverage of seminars, conferences and festivals related to the 
subject of the publication; valuing other Turkic-speaking peoples of Iran such as the Qashqai, Turkmen and Khalaj; proper attention to the issues of other Iranian ethnicities including Arabs, Baluchis, and so forth; philology and etymology and spelling issues related to Turkic and Turkic pages for children.

Such an approach that some government officials have adopted for their cultural and media activities demonstrate a considerable shift compared to the early nineties. Also, another example of a shift in the negative mindset of the Azerbaijani representatives towards ethnicity showed itself during Khatami's cabinet elections. Nearly seventy parliament members from cities in Azerbaijan stressed that at least two of the ministers in the cabinet had to be chosen from Azerbaijan MPs. Eventually, following a series of challenges, two Azerbaijani ministers, Mr. Pezishkiyan and Mr. Abdulali were elected to the cabinet. In addition, following several months of lobbying and negotiation between the Ministry of Interior and Azeri MPs emphasizing that the new provincial governors for East and West Azerbaijan and Ardabil and Zanjan should be indigenous to these provinces, two locally born governors were selected for East and West Azerbaijan.

\section{Social MesSeS}

In the social masses some signs of ethnic awareness and sectarian identity demands can be referred to. Among the social mass there is conspicuous capacity for ethnic mobilizability or ethnic identity. At different times, whether in the press or during elections calls for ethnic demands have been welcomed by the people. For example, in parliamentary elections in Tabriz in 1995, unsupported by special social groups, a less known candidate whose campaign centered on realization of cultural and civic demands ranked amongst the top candidates between one hundred or so individuals running in the elections. According to the figures published by the Tabriz governor and in comparison with other representatives, this MP managed to obtain one hundred and ten thousand votes, a figure that clearly indicated the degree of ethnic mobilizability within a short period of time.

The fifth parliamentary elections can be regarded as a turning point in the emergence of tendencies and ethnic affiliations of the people of Tabriz in the decades after Democratic Party. In contrast to previous elections where public turnouts usually ranged between 50 and 55 percent of eligible voters, more than 70 percent of the people voted. There was unprecedented excitement and exhilaration for the election of the said candidate in Tabriz in sharp contrast to Council of Experts elections in 1990 in which only $36 \%$ of people of Tabriz voted, marking the lowest participation rates in the country. Whereas just a year before, in 1997, Mr.Khatami's plans to improve cultural and ethnic demands and the hopes for sociopolitical as well as economic reforms won him the highest number of votes in the country to date. This is indicative of the fact that people's approach to elections is no longer of an emotional nature but one which is derived from a social consciousness that has arisen from their political and social awareness as observed in the contemporary history of the country.

Also, the social masses' gravitation to ethnically oriented press is noticeable. In this regard, two publications will be briefly introduced here:

As the most important periodical interested in ethnic and regional issues, Shams Tabriz Newspaper, which was first published as a bi-weekly in 1998 with a circulation of 2000, was soon received by public interest so much so that it circulation raised to 20000 within two months of its first issue. In other words, its circulation increased by 10 times since its first release. Similarly, another periodical interested in ethnic demands, i.e. Navid-e Azerbaijan, managed to publish twice a week just after a year of being a weekly paper, increasing its circulation to 20000 within two years from an initial 2000 representing significant public interest in ethnicity-related issues. As a final case regarding the issue of the behavior of social masses, mention should be made of the annual public gathering to commemorate the birth of BabakKhoramdin who revolted against Abbasid Caliphate. The ceremony was formerly attended by a small group of student activists and other interested individuals until 1999 until it turned into a big phenomenon encompassing the entire society. According to the published statistics, 30000 to 100000 people attended the event in the Babak Castle in 1999. The figure exceeded 100000 and reached 200000 in the following year. Also, in 2001, the public interest in this historical figure and symbol of social identity continued to increase culminating in a gathering of plus 200000 enthusiasts at the Babak Castle located $150 \mathrm{~km}$ from Tabriz. 


\section{Conclusion}

The situation for ethnic movement in Azerbaijan can be summarized as follows:

1. From the perspective of ethnic ideology, ethnicity-oriented activities in Azerbaijan are based on the rights of ethnic minorities as envisaged in the Constitution. The ethnic ideology of the movement pursues justice and seeks to eliminate cultural and economic constraints within the system and the constitution representing a clear internal movement and an expression of its demands in comparison to previous socio-political movements in Azerbaijan.

2. In terms of social status, the growth of the movement's driving force, i.e. the educated class and students, is clearly evident. Also, acceptance of the movement's goals and civil rights demands by the authorities and the governing elite in Azerbaijan can be observed.

3. In terms of the methods and mechanisms to pursue their demands, ethnic activists have adopted cultural and civic practices, gradually trying to institutionalize and organize their political activities. Also, a transition from certain emotional to organizational approaches is observable as is indicated in the interest in the official registration of several political organizations and cultural activities in Tabriz and Tehran and a tendency to avoid violence and conflict.

The final point in response to the ethnic issues in our country is that in the new era of coexistence of nations and human societies that form the pillars of nationality, citizenship and civil rights, it is essential that the Islamic Republic of Iran with regards to the conciliatory attitude of civil and ethnic movements in Azerbaijan - irrespective of some brushwood that can grow on the sidelines of this movement that may promote extremism- have legal and constitutional responses to this movement, because the absence of such responses would result in a gap between the activists - mostly including the educated class and the social, cultural and scientific elites - and the government. Naturally, the continuation of such a divide and obstruction of this movement will incur costs for the system as observed in experiences of other countries in the last century. This means that violent responses or even disregard towards peaceful social and cultural movements may force them to seek non-peaceful methods for the realization of their demands. Therefore, it is hoped that the system adopts a wise approach that is based on the constitution to respond to this movement and thereby avoid any future extremism. [11]

\section{REFERENCES}

[1] Sheikhavandi, Davar (1989). "the rise and birth of a nation". Qoqnoos publications. Tehran.P.19

[2] SeyedEmami, Keikavoos (1998). National unity and growth of ethnic approaches. "Journal of Strategic Studies". Spring 1998. P. 10

[3] Sheikhavandi, Davar (1989). "the rise and birth of a nation". Qoqnoos publications. Tehran.P.37

[4] Sheikhavandi, Davar (1989). "the rise and birth of a nation". Qoqnoos publications. Tehran.P.40

[5] Sabetfar, Morteza (1991). "Iranian nationalism and the issues on nations in Iran". Negah publications. Tehran. P. 34

[6] J.A. De Gobineau, Trois ansen Asia Ed. A.M. Metalic, Paris 1980, P.20

[7] Enkhabi, Nader (1992). "Nationalism and Modernity in Iran after the Constitutional Revolution".Negah publications. Tehran. P. 51

[8] Ahmadi, Hamid (2008). "Ethnicity and modernity in Iran". Ney publications. Tehran. P. 143

[9] Sabetfar, Morteza (1991). "Iranian nationalism and the issues on nations in Iran". Negah publications. Tehran. P. 42

[10] Enayat, hamid (2008). "New political thinking in Azerbaijan ethnicity". Akhtar publications. Tabriz. P. 28. 